\title{
Testing the hypothesis of a recombinant origin of the SARS-associated coronavirus
}

\author{
X. W. Zhang ${ }^{1}$, Y. L. Yap ${ }^{1}$, and A. Danchin ${ }^{2}$ \\ ${ }^{1}$ HKU-Pasteur Research Centre, Hong Kong, P.R. China \\ ${ }^{2}$ Pasteur Institute, Unit Genetics of Bacterial Genomes, Paris, France
}

Received February 27, 2004; accepted August 16, 2004

Published online October 11, 2004 (C) Springer-Verlag 2004

Summary. The origin of severe acute respiratory syndrome-associated coronavirus (SARS-CoV) is still a matter of speculation, although more than one year has passed since the onset of the SARS outbreak. In this study, we implemented a 3-step strategy to test the intriguing hypothesis that SARS-CoV might have been derived from a recombinant virus. First, we blasted the whole SARS-CoV genome against a virus database to search viruses of interest. Second, we employed 7 recombination detection techniques well documented in successfully detecting recombination events to explore the presence of recombination in SARS-CoV genome. Finally, we conducted phylogenetic analyses to further explore whether recombination has indeed occurred in the course of coronaviruses history predating the emergence of SARS-CoV. Surprisingly, we found that 7 putative recombination regions, located in Replicase $1 \mathrm{ab}$ and Spike protein, exist between SARS-CoV and other 6 coronaviruses: porcine epidemic diarrhea virus (PEDV), transmissible gastroenteritis virus (TGEV), bovine coronavirus (BCoV), human coronavirus 229E ( $\mathrm{HCoV})$, murine hepatitis virus (MHV), and avian infectious bronchitis virus (IBV). Thus, our analyses substantiate the presence of recombination events in history that led to the SARS-CoV genome. Like the other coronaviruses used in the analysis, SARS-CoV is also a mosaic structure.

\section{Introduction}

SARS, a new disease characterized by high fever, malaise, rigor, headache and non-productive cough, has spread to over 30 countries with around $8 \%$ of mortality rate on average. Sequence analysis of SARS coronavirus (SARS-CoV) $[17,25]$ showed that it is a novel coronavirus [12]. Anand et al. [1] reported a three-dimensional model of SARS-CoV main proteinase and suggested that 
modified rhinovirus $3 C^{\text {pro }}$ inhibitors could be useful for SARS therapy. Lipsitch et al. [15] developed a mathematical model of SARS transmission to estimate the infectiousness of SARS and the likelihood of an outbreak. $\mathrm{Ng}$ et al. [22] suggested that SARS-CoV could have been derived from an innocuous virus or oen causing a mild disease, that would become virulent after some mutational event occuring in some carriers. However, the source of SARS-CoV is not yet exactly known, although it has been reported that a virus highly related to SARS$\mathrm{CoV}$ has infected some wild animals, such as masked palm civet, raccoon dog and badger [7].

Recombination, a key evolutionary process, accounts for a considerable amount of genetic diversity in natural populations. The occurrence of highfrequency homologous RNA recombination is one of the most intriguing aspects of coronavirus replication [14, 27, 31, 34]. The first experimental evidence for IBV recombination was found by Kottier et al. [11], although other studies have concluded that recombination is a feature of IBV evolution [4, 5, 10, 36-38]. Recombination in MHV was also experimentally demonstrated [16]. In particular, Snijder et al. [30] indicated that the recombination occurred between a coronavirus/torovirus-like virus and an influenza $\mathrm{C}$-like virus, resulting in a line of coronaviruses that had a haemagglutinin esterase (HE) gene. This prompted us to explore the possible role of recombination in the emergence of SARS-CoV. A recent report indicated that SARS-CoV has been found in a number of wild animals with $99.8 \%$ identity [7]. What would be the role of recombination in the event that created this virus, possibly in a predator animal?

Stavrinides and Guttman [32] have suggested that a possible past recombination event between mammalian-like and avian-like parent viruses is responsible for the evolution of SARS-CoV. In order to further test for the recombination hypothesis, we implemented a 3-step strategy. First, we employed BLAST to determine which viruses (coronaviruses or other viruses) should be included in the sample relevant for recombination detection analysis. Second, we used widely used recombination detection techniques to detect the occurrence of recombination between SARS-CoV and other coronaviruses. Finally, we used phylogenetic tree analysis to confirm the presence of recombination events.

\section{Materials and methods}

\section{Sequences}

A reference SARS-CoV genome sequence (NC_004718) [17] was downloaded from GenBank. In order to determine which viruses (coronaviruses or other viruses) should be included in the sample relevant for recombination detection analysis, we blasted the whole SARS-CoV sequence against virus database and the result indicated that there are 6 significant hits (at the level of E-value $<0.0001$. Table 1): Murine hepatitis virus (MHV), Porcine epidemic diarrhea virus (PEDV), Bovine coronavirus (BCoV), Transmissible gastroenteritis virus (TGEV), Avian infectious bronchitis virus (IBV) and Human coronavirus 229E (HCoV). All these sequences were downloaded from GenBank: MHV (AF029248), PEDV (AF353511), BCoV (NC_003045), TGEV (NC_002306), IBV (NC_001451) and HCoV (NC_002645). 
Table 1. Search results by BLAST

\begin{tabular}{lll}
\hline Virus & Score (bits) & E-value \\
\hline Murine hepatitis virus & 92 & $2.00 \mathrm{E}-16$ \\
Porcine epidemic diarrhea virus & 80 & $8.00 \mathrm{E}-13$ \\
Bovine coronavirus & 72 & $2.00 \mathrm{E}-10$ \\
Transmissible gastroenteritis virus & 58 & $3.00 \mathrm{E}-06$ \\
Avian infectious bronchitis virus & 58 & $3.00 \mathrm{E}-06$ \\
Human coronavirus 229E & 54 & $4.00 \mathrm{E}-05$ \\
Ovine astrovirus & 48 & 0.003 \\
Streptococcus pyogenes & 44 & 0.043 \\
Saccharomyces cerevisiae chromosome & 42 & 0.17 \\
Saccharomyces cerevisiae chromosome & 40 & 0.67 \\
Equine rhinitis B virus & 40 & 0.67 \\
Equine rhinovirus 3 & 40 & 0.67 \\
Callitrichine herpesvirus 3 & 40 & 0.67 \\
Turkey astrovirus & 40 & 0.67 \\
Amsacta moorei entomopoxvirus & 40 & 0.67 \\
Salmonella typhimurium bacteriophage & 38 & 2.7 \\
Goatpox virus & 38 & 2.7 \\
Bacteriophage SPBc2 & 38 & 2.7 \\
Saccharomyces cerevisiae chromosome & 38 & 2.7 \\
Shrimp white spot syndrome virus & 38 & 2.7 \\
Tupaia paramyxovirus & 38 & 2.7 \\
Rachiplusia ou multiple nucleohedrovirus & 38 & 2.7 \\
Lumpy skin disease virus & 38 & 2.7 \\
Sheeppox virus & 38 & 2.7 \\
Human papillomavirus type 59 & 38 & 2.7 \\
Citrus tristeza virus & 38 & 2.7 \\
Pseudomonas phage phiKZ & 38 & 2.7 \\
\hline & &
\end{tabular}

\section{Recombination detection and phylogenetic analysis}

There are a number of methods and software packages that have been developed for detection of recombination events in DNA sequences. The performance of these methods has been extensively evaluated and compared on simulated and real data [23, 24]. In the present study we applied these methods to RNA viruses. SARS-CoV and other 6 coronavirus genomes (SARS-CoV, IBV, BCoV, HCoV, MHV, PEDV, TGEV) were first aligned using CLUSTALW [33]. Sites with gaps were removed and a 25077-nt alignment was generated. Subsequently, seven methods were employed to detect the occurrence of recombination (see corresponding reference in parenthesis for details of each method): BOOTSCAN [26], GENECONV [28], DSS (Difference of Sums of Squares) [20], HMM (Hidden Markov Model) [8], MAXCHI (Maximum Chi-Square method) [19], PDM (Probabilistic Divergence Measures) [9], RDP (Recombination Detection Program) [18].

BOOTSCAN, MAXCHI and RDP are implemented in RDP software package, http://web.uct.ac.za/depts/microbiology/microdescription.htm. GENECONV is implemented in the program, http://www.math.wustl.edu/ sawyer/geneconv/. DSS, HMM and PDM are implemented in TOPALi software package, http://www.bioss.sari.ac.uk/software.html. 
Basically default parameter settings were used in all the programs, except the following values: gscale $=1($ GENECONV), internal and external references $(\mathrm{RDP})$, window size $=300$ and step $=10$ (DSS, HMM and PDM).

After potential recombination events were identified by at least 3 methods above, separate neighbor joining trees were constructed for each putative recombination region to better evaluate the evidence for conflicting evolutionary histories of different sequence regions. All trees were produced with TOPALi mentioned above.

\section{Results}

\section{Recombination detection}

Table 2 summarizes the results of BOOTSCAN analysis with 100\% bootstrap support and significant $\mathrm{P}$-value $(<0.05$ for uncorrected and MC corrected Pvalue). Two regions (13151-13299 and 16051-16449, position in alignment) are identified as putative recombination regions and all 6 coronaviruses are potential parents with SARS-CoV as potential daughter.

GENECONV detected 9 putative recombination events occurred in a wide range of positions 5941-24997 (in alignment) at a significant level $\mathrm{p}<0.05$ for two P-values: simulated P-value (based on 10,000 permutations) and BLASTlike BC KA P-value (Table 3). All 6 coronaviruses are potential parents with SARS-CoV as potential daughter.

MAXCHI identified 15 putative recombination events (Table 4, possible misidentification events are not retained). Most of the breakpoints are significant at about 0.001 level; the position located in alignment spans from 3534 to 22840 , but some beginning or ending breakpoints are not determined. Similarly, 6 coronaviruses are potential parents with SARS-CoV as potential daughter.

RDP revealed that 6 putative recombination events occur in the domain of alignment 5910-13334 (Table 5), with the uncorrected and MC corrected pvalue at less than 0.002 and 0.05 respectively. In this case, 4 coronaviruses (IBV, BCoV, MHV and PEDV) are potential parents with SARS-CoV as potential daughter.

Figure 1 shows the DSS profiles of putative breakpoints between SARS-CoV and other coronaviruses (Dotted line indicates the 95 percentile under the null hypothesis of no recombination): SARS-CoV, IBV, BCoV and MHV (Fig. 1a), SARS-CoV, MHV, PEDV and TGEV (Fig. 1b), SARS-CoV, IBV, HCoV and TGEV (Fig. 1c). There are about 6 different breakpoints (significant peaks): 13614 and 16085 (Fig. 1a), 11008 and 12850 (Fig. 1b), 12805, 13614 and 16444 (Fig. 1c).

HMM plots for SARS-CoV, IBV, BCoV and $\mathrm{HCoV}$ (Fig. 2) revealed that the putative breakpoints are at about position 5500 and 19000. There is a clear transition from state 1 (SARS-CoV grouped with IBV) (Fig. 2a) into state 3 (SARS-CoV grouped with HCoV) (Fig. 2c). The region between 5500 and 19000 is noisy, and at this moment no information can be provided by HMM.

Figure 3 shows the results of PDM analysis performed on SARS-CoV and other coronaviruses (dotted line indicates the 95\% critical region for the null 


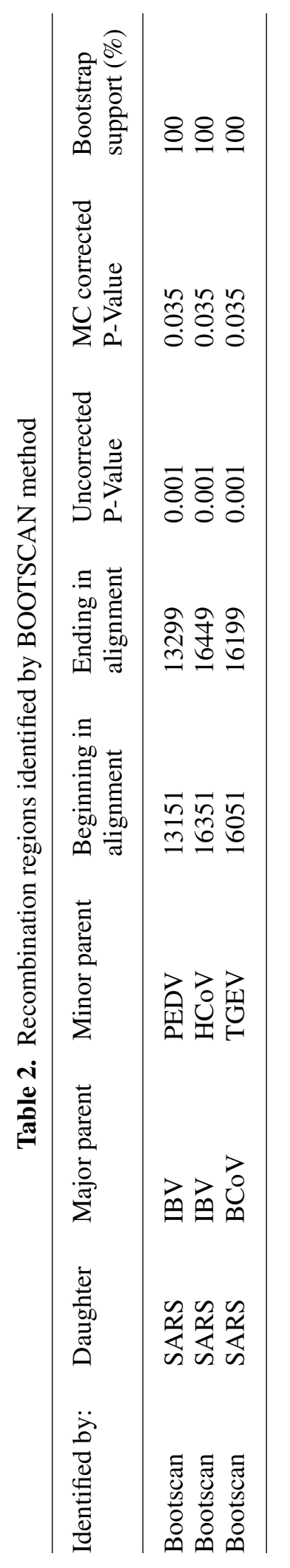


Table 3. Recombination regions identified by GENECONV method

\begin{tabular}{lllllll}
\hline Identified by: & Daughter & Parent & $\begin{array}{l}\text { Beginning in } \\
\text { alignment }\end{array}$ & $\begin{array}{l}\text { Ending in } \\
\text { alignment }\end{array}$ & $\begin{array}{l}\text { Simulated } \\
\text { P-Value }\end{array}$ & $\begin{array}{l}\text { BC KA } \\
\text { P-Value }\end{array}$ \\
\hline GENECONV & SARS & IBV & 24970 & 24997 & 0.0001 & 0.00003 \\
GENECONV & SARS & IBV & 20708 & 20727 & 0.0156 & 0.0172 \\
GENECONV & SARS & BCoV & 12102 & 12135 & 0.0329 & 0.04634 \\
GENECONV & SARS & BCoV & 11977 & 12024 & 0.0051 & 0.00509 \\
GENECONV & SARS & BCoV & 5941 & 5965 & 0.0051 & 0.00509 \\
GENECONV & SARS & HCoV & 10491 & 10524 & 0.0033 & 0.00361 \\
GENECONV & SARS & MHV & 12595 & 12664 & 0.0185 & 0.01999 \\
GENECONV & SARS & PEDV & 13208 & 13263 & 0.0076 & 0.00827 \\
GENECONV & SARS & TGEV & 8399 & 8425 & 0.0315 & 0.02951 \\
\hline
\end{tabular}

Table 4. Recombination regions identified by MAXCHI method

\begin{tabular}{|c|c|c|c|c|c|c|c|}
\hline Identified by: & Daughter & $\begin{array}{l}\text { Major } \\
\text { parent }\end{array}$ & $\begin{array}{l}\text { Minor } \\
\text { parent }\end{array}$ & $\begin{array}{l}\text { Beginning in } \\
\text { alignment }\end{array}$ & $\begin{array}{l}\text { Ending in } \\
\text { alignment }\end{array}$ & $\begin{array}{l}\text { Beginning } \\
\text { breakpoint } \\
\text { P-Value }\end{array}$ & $\begin{array}{l}\text { Ending } \\
\text { breakpoint } \\
\text { P-Value }\end{array}$ \\
\hline Maxchi & SARS & PEDV & TGEV & 9052 & 9066 & 0.028108 & 0.00065 \\
\hline Maxchi & SARS & IBV & $\mathrm{HCoV}$ & undetermined & 5486 & - & 0.000336 \\
\hline Maxchi & SARS & $\mathrm{HCoV}$ & IBV & 14026 & undetermined & 0.000913 & - \\
\hline Maxchi & SARS & PEDV & TGEV & 10668 & undetermined & 0.000957 & - \\
\hline Maxchi & SARS & $\begin{array}{l}\text { Unknown } \\
\text { (MHV) }\end{array}$ & IBV & 20676 & 22840 & 0.000913 & 0.000913 \\
\hline Maxchi & SARS & $\begin{array}{l}\text { Unknown } \\
\text { (MHV) }\end{array}$ & IBV & undetermined & 8996 & - & 0.000957 \\
\hline Maxchi & SARS & MHV & $\mathrm{BCoV}$ & 16609 & undetermined & 0.000913 & - \\
\hline Maxchi & SARS & MHV & $\mathrm{BCoV}$ & 20514 & undetermined & $7.75 \mathrm{E}-06$ & - \\
\hline Maxchi & SARS & MHV & $\mathrm{HCoV}$ & undetermined & 3534 & - & 0.000336 \\
\hline Maxchi & SARS & PEDV & $\mathrm{HCoV}$ & 18528 & undetermined & 0.001015 & - \\
\hline Maxchi & SARS & PEDV & $\mathrm{HCoV}$ & undetermined & 7281 & - & 0.00065 \\
\hline Maxchi & SARS & PEDV & $\mathrm{HCoV}$ & 15742 & 15763 & 0.001015 & 0.009907 \\
\hline Maxchi & SARS & $\mathrm{HCoV}$ & PEDV & 9137 & 9156 & 0.000913 & 0.010587 \\
\hline Maxchi & SARS & PEDV & $\mathrm{HCoV}$ & 5474 & undetermined & 0.000957 & - \\
\hline Maxchi & SARS & $\mathrm{HCoV}$ & TGEV & 12854 & undetermined & 0.000253 & - \\
\hline
\end{tabular}

Table 5. Recombination regions identified by RDP method

\begin{tabular}{llllcccc}
\hline Identified by: & Daughter & $\begin{array}{l}\text { Major } \\
\text { parent }\end{array}$ & $\begin{array}{l}\text { Minor } \\
\text { parent }\end{array}$ & $\begin{array}{l}\text { Beginning in } \\
\text { alignment }\end{array}$ & $\begin{array}{l}\text { Ending in } \\
\text { alignment }\end{array}$ & $\begin{array}{l}\text { Uncorrected } \\
\text { P-Value }\end{array}$ & $\begin{array}{l}\text { MC corrected } \\
\text { P-value }\end{array}$ \\
\hline RDP & SARS & IBV & BCoV & 5910 & 6111 & $5.18 \mathrm{E}-04$ & $1.81 \mathrm{E}-02$ \\
RDP & SARS & IBV & BCoV & 6136 & 6286 & $1.56 \mathrm{E}-05$ & $5.45 \mathrm{E}-04$ \\
RDP & SARS & IBV & MHV & 6134 & 6326 & $1.28 \mathrm{E}-03$ & $4.49 \mathrm{E}-02$ \\
RDP & SARS & BCoV & PEDV & 13151 & 13280 & $3.32 \mathrm{E}-04$ & $1.16 \mathrm{E}-02$ \\
RDP & SARS & MHV & PEDV & 9196 & 9334 & $1.72 \mathrm{E}-05$ & $6.03 \mathrm{E}-04$ \\
RDP & SARS & MHV & PEDV & 13152 & 13334 & $3.89 \mathrm{E}-05$ & $1.36 \mathrm{E}-03$ \\
\hline
\end{tabular}



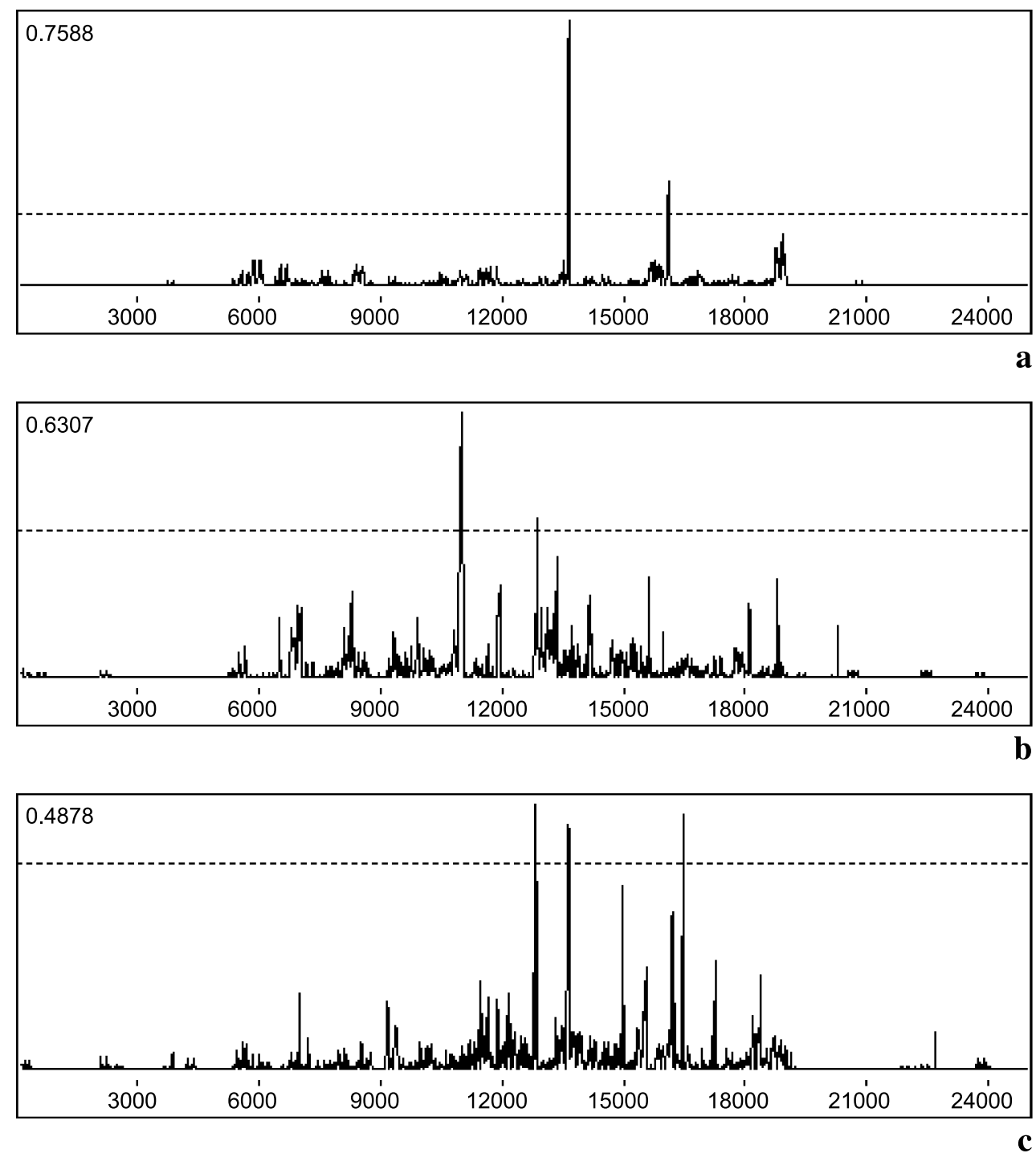

Fig. 1. Predicting recombination regions with DSS (Difference of Sums of Squares) implemented in TOPALi. Default parameter values were used except for the Fitch method, where a window size $=300$ and step $=10$ were chosen. The horizontal axis represents the site in the alignment, the vertical axis represents the DSS statistic, and the dotted line shows the 95 percentile under the null hypothesis of no recombination. SARS-CoV, IBV, BCoV and MHV for Fig. 1a, SARS-CoV, MHV, PEDV and TGEV for Fig. 1b, and SARS-CoV, IBV, HcoV and TGEV for Fig. 1c, where SARS-CoV-severe acute respiratory syndrome-associated coronavirus, PEDV-porcine epidemic diarrhea virus, TGEV-transmissible gastroenteritis virus, $\mathrm{BCoV}$-bovine coronavirus, $\mathrm{HCoV}$-human coronavirus, $\mathrm{MHV}$-murine hepatitis virus, and IBV-avian infectious bronchitis virus

hypothesis of no recombination): SARS-CoV, IBV, BCoV and MHV (Fig. 3a, b), SARS-CoV, MHV, PEDV and TGEV (Fig. 3c, d), SARS-CoV, BCoV, HCoV and MHV (Fig. 3e, f). A number of breakpoints (pronounced peaks) could be concurred: 6380, 13479, 18915 and 20263 (Fig. 3a, b), 1753, 5032, 9256, 10289, 

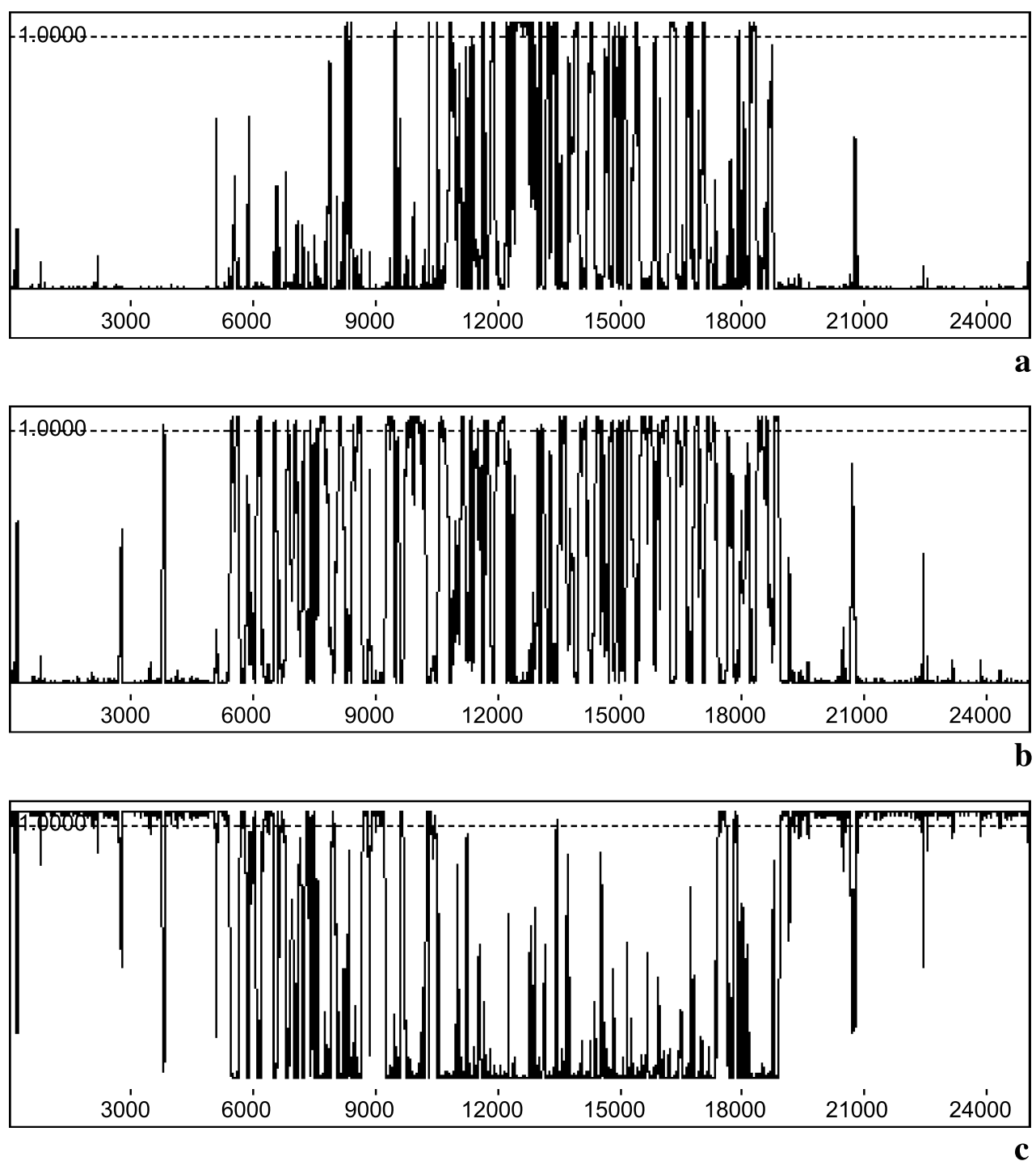

Fig. 2. Predicting recombination regions with HMM (Hidden Markov Model) implemented in TOPALi. Default parameter values were used. The horizontal axis represents the site in the alignment, the vertical axis represents the probability for topology change, and the dotted line shows the 95 percentile under the null hypothesis of no recombination. SARS-CoV, IBV, BCoV and $\mathrm{HCoV}$ was used, where SARS-CoV-severe acute respiratory syndrome-associated coronavirus, $\mathrm{BCoV}$-bovine coronavirus, $\mathrm{HCoV}$-human coronavirus, and IBV-avian infectious bronchitis virus

15591, 19050 and 22195 (Fig. 3c, d), 1393, 6111, 16624, 19859 and 20802 (Fig. 3e, f).

Posada [23] suggested that one should not rely too much on a single method for recombination detection. Here we consider the regions identified by at least 3 methods as putative recombination regions. The results are summarized in Table 6. Seven putative recombination regions span a range of positions in SARS-CoV 

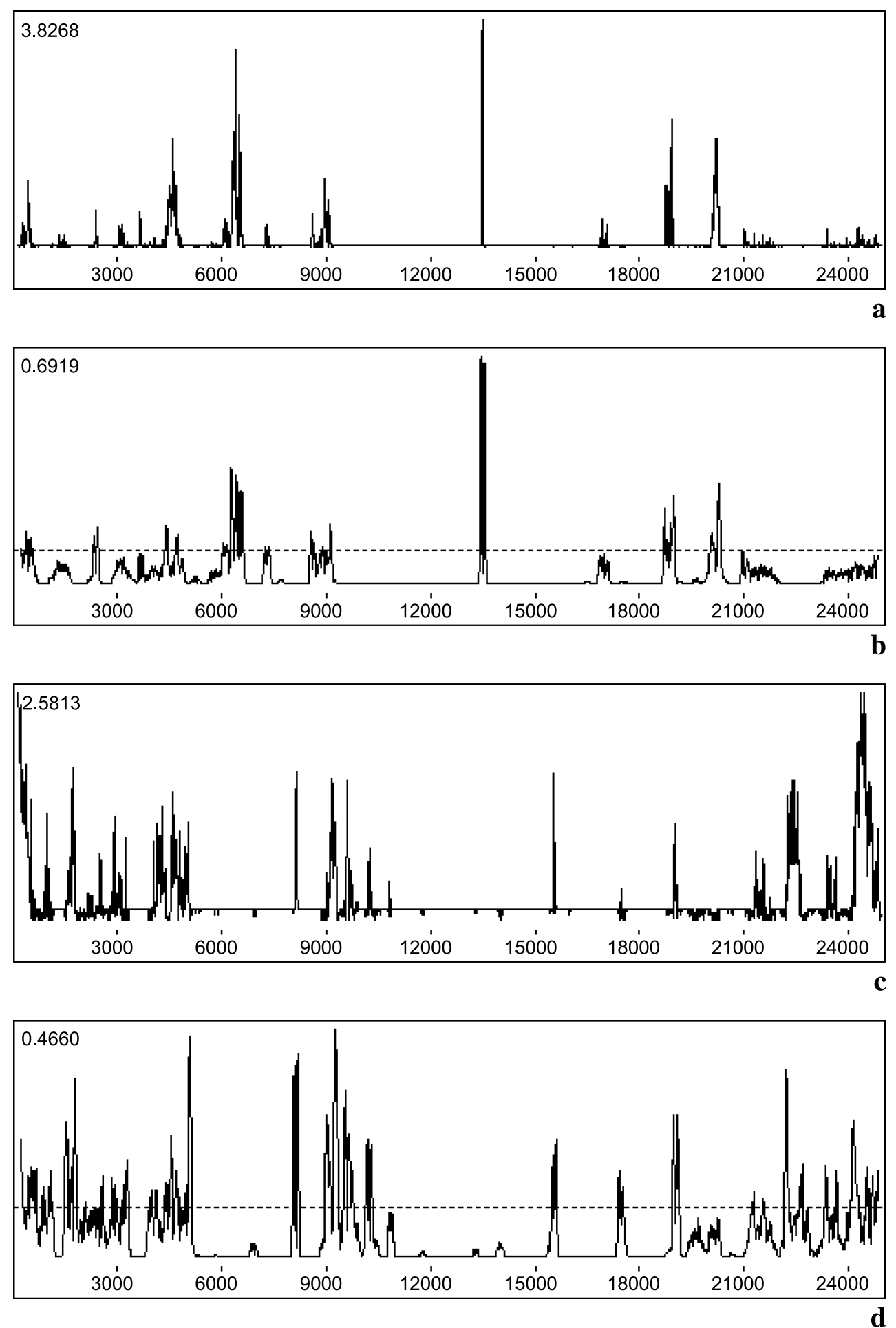

Fig. 3 (continued) 

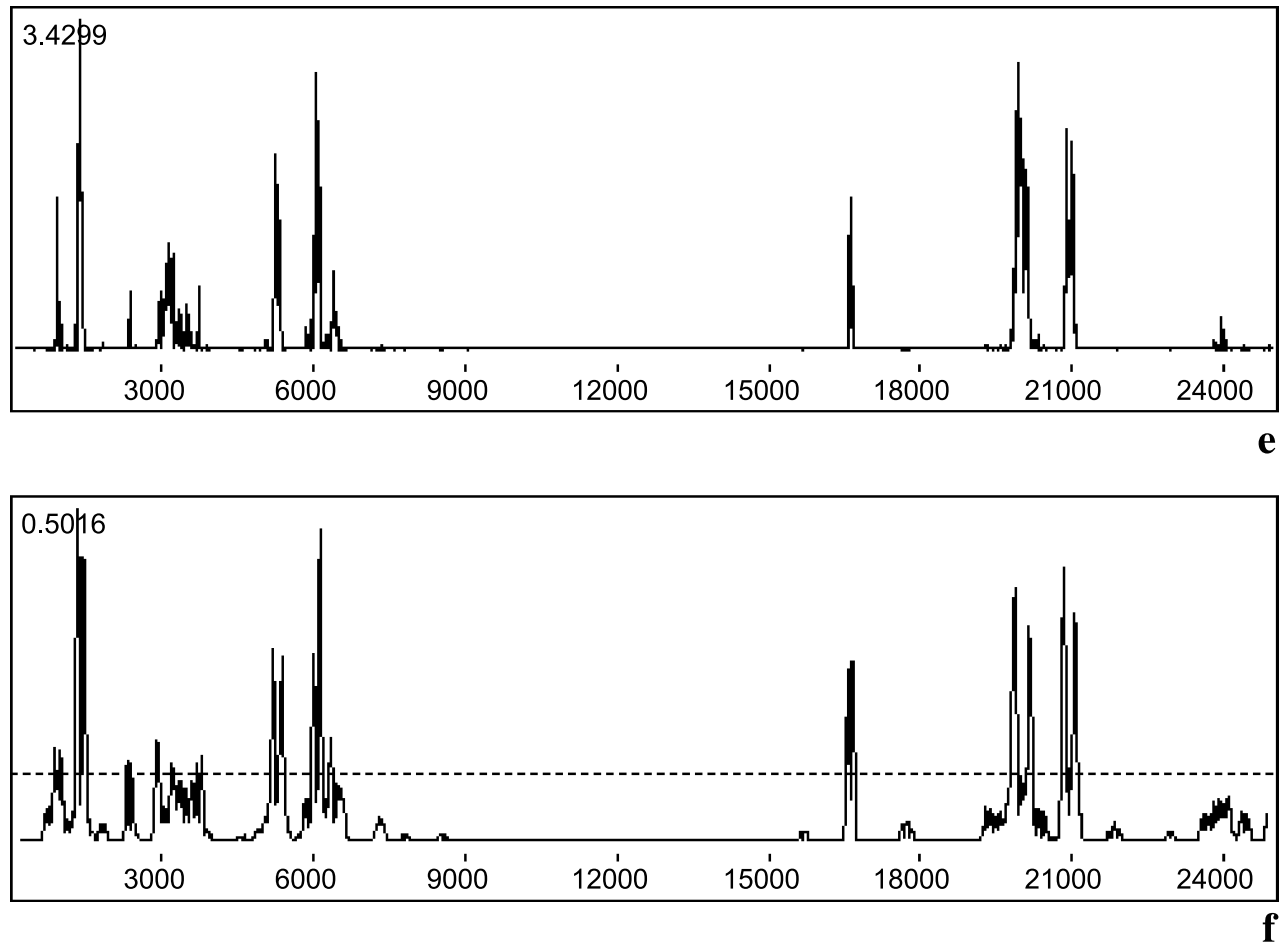

Fig. 3. Predicting recombination regions with PDM (Probabilistic Divergence Measures) implemented in TOPALi. Default parameter values were used with the exception that window size $=300$ and step $=10$ were used. The horizontal axis represents the site in the alignment, the vertical axis represents the global and local divergence measures, and the dotted line shows the $95 \%$ critical region for the null hypothesis of no recombination. SARS-CoV, IBV, BCoV and MHV for Fig. 3a, b, SARS-CoV, MHV, PEDV and TGEV for Fig. 3c, d, and SARS-CoV, BCoV, $\mathrm{HcoV}$ and $\mathrm{MHV}$ for Fig. 3e, f, where SARS-CoV-severe acute respiratory syndrome-associated coronavirus, PEDV-porcine epidemic diarrhea virus, TGEVtransmissible gastroenteritis virus, $\mathrm{BCoV}$-bovine coronavirus, $\mathrm{HCoV}$-human coronavirus, MHV-murine hepatitis virus, and IBV-avian infectious bronchitis virus

genome from 7475-24133. These regions are separately extracted for phylogenetic analysis.

\section{Phylogenetic analysis}

Phylogenetic trees constructed by using putative recombination regions and nonrecombination regions identified by above techniques are shown in Figure 4. The left panels stand for non-recombination regions and the right panels for recombination regions. We compared each row of figures and found that the phylogenetic tree in the left panel (non-recombination region) had very different topology when compared to the phylogenetic tree in the right panel (recombination region), which indicates that recombination has occurred. For example, in Fig. 4a, 7 coronaviruses are divided into 4 groups: group 1 for TGEV, HCoV and PEDV, group 2 for $\mathrm{BCoV}$ and $\mathrm{MHV}$, group 3 for IBV, and group 4 for SARS-CoV, consistent with Marra et al. [17]; while in Fig. 4b, 7 coronaviruses are divided 


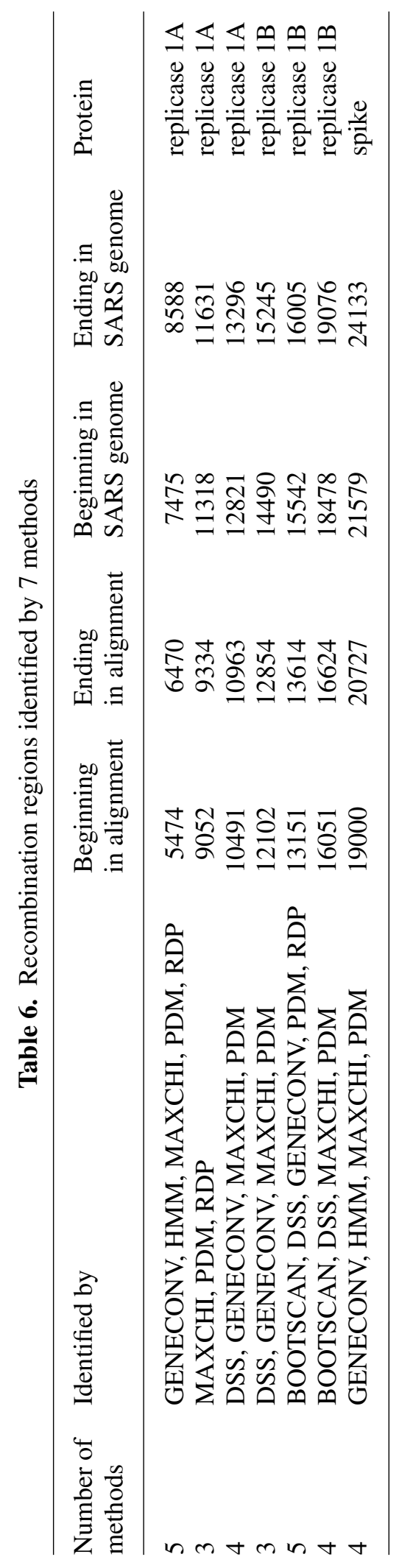


Non-recombination regions

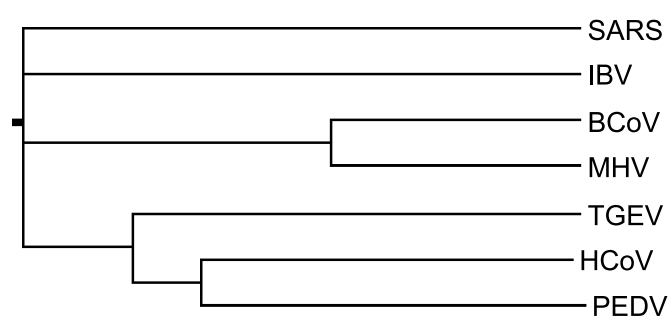

0.1 Expected Substitutions per Site

a Region 1-5473

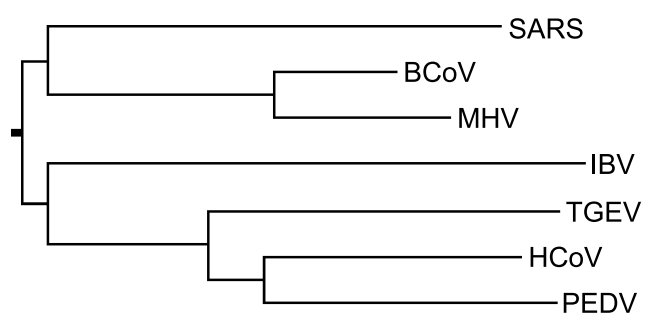

0.1 Expected Substitutions per Site

c Region 6471-9051

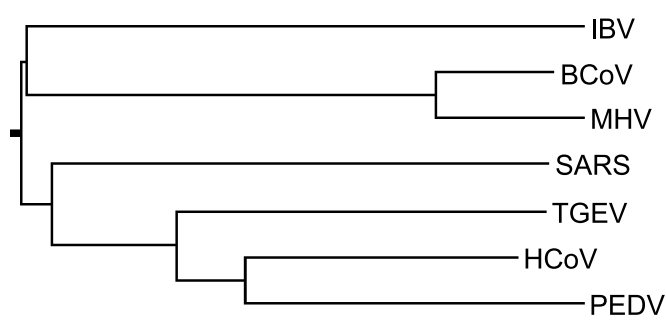

0.1 Expected Substitutions per Site

e Region 9335-10490

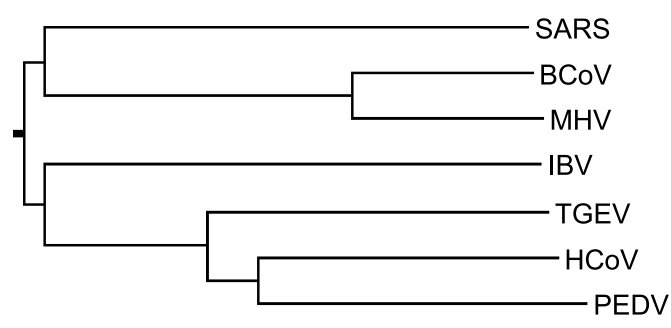

0.1 Expected Substitutions per Site

g Region 10964-12101

\section{Recombination regions}

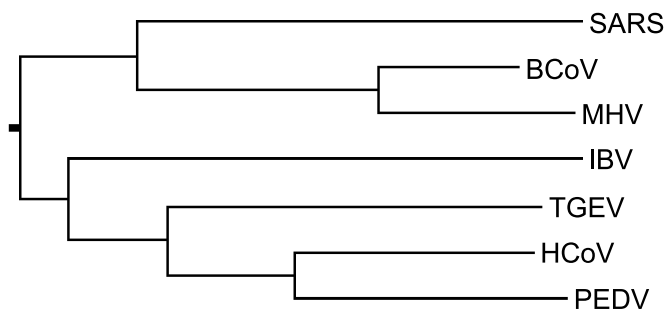

0.1 Expected Substitutions per Site

b Region 5474-6470

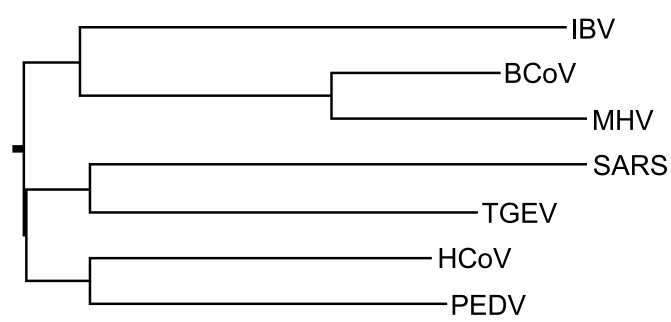

0.1 Expected Substitutions per Site

d Region 9052-9334

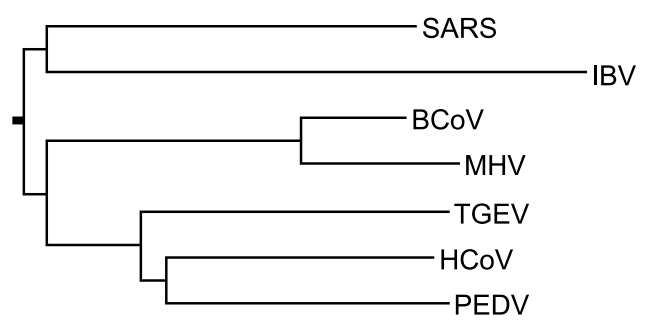

0.1 Expected Substitutions per Site

f Region 10491-10963

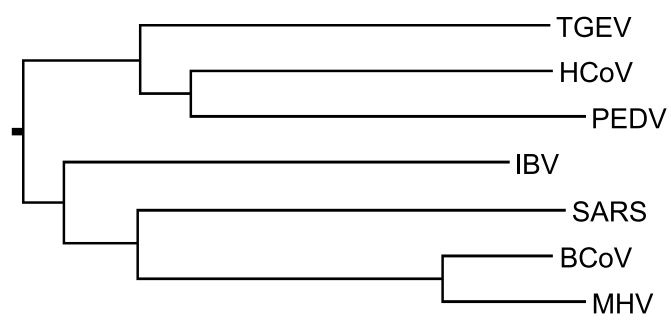

0.1 Expected Substitutions per Site

h Region 12102-12854

Fig. 4 (continued) 
Non-recombination regions

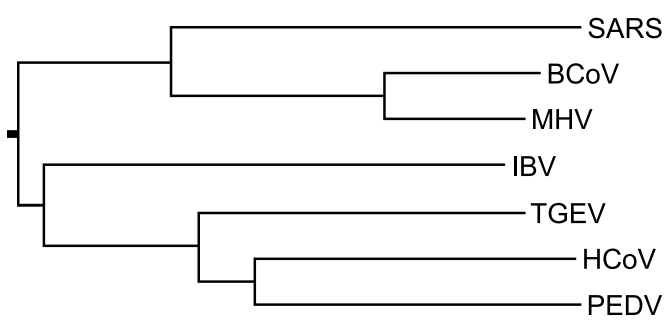

0.1 Expected Substitutions per Site

i Region 12855-13150

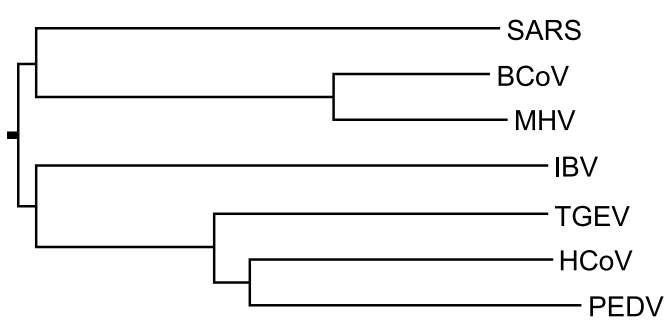

0.1 Expected Substitutions per Site

k Region 13615-16050

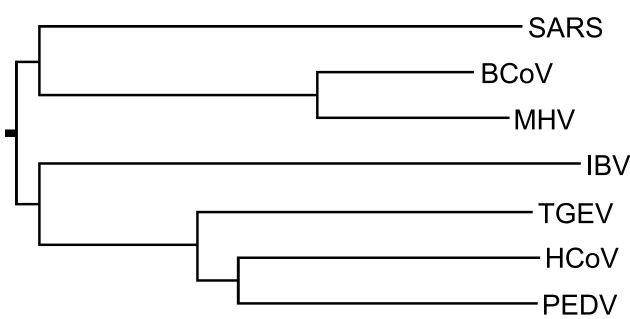

0.1 Expected Substitutions per Site

m Region 16625-18999
Recombination regions

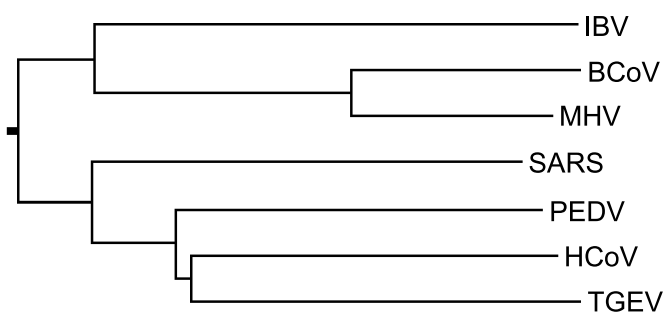

0.1 Expected Substitutions per Site

j Region 13151-13614

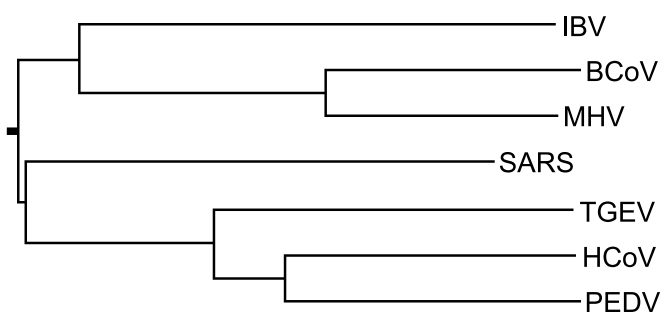

0.1 Expected Substitutions per Site

I Region 16051-16624

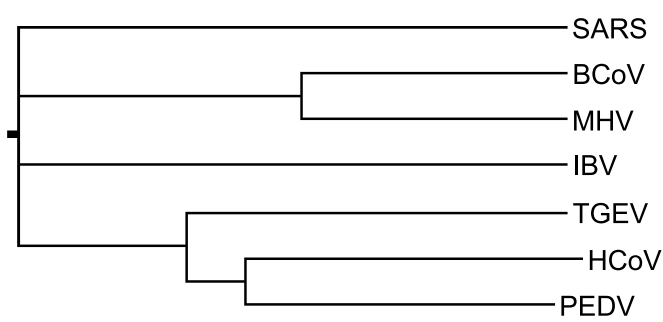

0.1 Expected Substitutions per Site

n Region 19000-20727

Fig. 4. Phylogenetic analysis of putative recombination regions. Neighbour joining trees were constructed by TOPALi. The sequence region in the alignment used for each tree is written below each figure. The phylogenetic trees in the left panel correspond to non-recombination region and the phylogenetic trees in the right panel correspond to recombination region. All branch lengths are drawn to scale. Six coronaviruses (IBV, BCoV, HCoV, MHV, PEDV and TGEV) are potential parents of SARS-CoV, where SARS-CoV-severe acute respiratory syndrome-associated coronavirus, PEDV-porcine epidemic diarrhea virus, TGEVtransmissible gastroenteritis virus, $\mathrm{BCoV}$-bovine coronavirus, HCoV-human coronavirus, $\mathrm{MHV}$-murine hepatitis virus, and IBV-avian infectious bronchitis virus

into 2 groups: group 1 for IBV, TGEV, HCoV and PEDV, group 2 for BCoV, MHV and SARS-CoV, suggests that SARS-CoV is most closely related to BCoV and $\mathrm{MHV}$, which is consistent with a recent report [29]. At the same time, SARS-CoV 
is also most closely related to TGEV (Fig. 4d) and IBV (Fig. 4f). Thus, phylogenetic analysis substantiates the presence of recombination events in the history that led to the SARS-CoV genome.

\section{Discussion}

In this study, seven recombination detection methods and phylogenetic analyses were performed on SARS-CoV and the six coronaviruses identified by BLAST (IBV, BCoV, HCoV, MHV, PEDV and TGEV). These techniques successfully identified recombination events in bacteria and viruses [2, 3, 6, 21, 26, 39]. Our analysis concurred to suggest the occurrence of recombination events between ancestors of SARS-CoV and these 6 coronaviruses. Indeed, pairwise alignment showed that many segments of high homology with IBV, BCoV, HCoV, MHV, PEDV and TGEV do exist in SARS-CoV genome, Table 7 exhibits the segments with length $>20$ nt and identiy $>80 \%$, and Fig. 5 shows the mosaic structure of the region 14930-15908 in SARS-CoV genome based on the segments with length $>50$ and identity $>80 \%$. Of course, the other coronaviruses used in the analysis are also mosaic structures, for more sequence similarities exist among them than with SARS-CoV.

It is noted that all the sequence comparisons in this study are based on nucleotide sequences. While the protein sequences in SARS-CoV are largely different from those in the known three groups of coronavirus [17], such as, for $S$ protein, the identity is: $25.9 \%$ for SARS-CoV and BCoV, $21.7 \%$ for SARS-CoV and $\mathrm{HCoV}, 21.5 \%$ for SARS-CoV and IBV, 25.6\% for SARS-CoV and MHV, $20.6 \%$ for SARS-CoV and PEDV, 19.4\% for SARS-CoV and TGEV. Although SARS-CoV is close to $\mathrm{BCoV}, \mathrm{MHV}$, TGEV and IBV, the corresponding protein, replicase 1a, is still different: with identity $27.4 \%$ for SARS-CoV and BCoV, $24.8 \%$ for SARS-CoV and IBV, 32.2\% for SARS-CoV and MHV, 25.0\% for SARS-CoV and TGEV.

Naturally, we should take into account the role of convergent evolution, which would bear its mark on the viral genome. The recombination events that we witnessed in SARS-CoV are present in six different viruses, suggesting sequential horizontal transfers and progressive adaptation to new hosts cells or animals. Indeed because viruses need both receptors to permeate host cells and resist the immune response of the host, their outer layer proteins are submitted to an extremely strong selection pressure that may restrict considerably the possible variations of the corresponding proteins (and accordingly of the corresponding genome pieces of sequences). It is nevertheless remarkable that, despite the inclusion of all possible types of viruses in our sample set (as well as shuffled genomes from the viruses we have identified as relevant) we find a more or less single category of viruses as similar to SARS-CoV. This suggests that even if the contribution of convergent evolution is important, this happened on a more or less common phylogenetic background, suggesting several steps of recombination followed by fine adaptation. In this context, we would like to suggest that ancestors of PEDV, MHV or both are the most plausible origin of SARS-CoV. Guan et al. [7] 
Table 7. Mosaic segments in SARS-CoV genome (length $>20$ nt and identity $>80 \%$ )

\begin{tabular}{|c|c|c|c|c|c|}
\hline $\begin{array}{l}\text { Beginning in } \\
\text { SARS }\end{array}$ & $\begin{array}{l}\text { Ending in } \\
\text { SARS }\end{array}$ & Length & Identity & $\begin{array}{l}\text { Match percent } \\
(\%)\end{array}$ & Source \\
\hline 10063 & 10109 & 47 & 41 & 88 & MHV \\
\hline 10609 & 10641 & 33 & 30 & 91 & TGEV \\
\hline 12821 & 12854 & 34 & 31 & 92 & $\mathrm{HCoV}$ \\
\hline 13844 & 13879 & 36 & 32 & 89 & $\mathrm{BCoV}$ \\
\hline 13845 & 13879 & 35 & 31 & 89 & MHV \\
\hline 13986 & 14011 & 26 & 26 & 100 & PEDV \\
\hline 14365 & 14412 & 48 & 45 & 94 & $\mathrm{BCoV}$ \\
\hline 14367 & 14395 & 29 & 27 & 94 & MHV \\
\hline 14490 & 14523 & 34 & 32 & 95 & $\mathrm{BCoV}$ \\
\hline 14589 & 14632 & 44 & 38 & 87 & $\mathrm{BCoV}$ \\
\hline 14685 & 14729 & 45 & 39 & 87 & MHV \\
\hline 14724 & 14746 & 23 & 22 & 96 & IBV \\
\hline 14808 & 14835 & 28 & 26 & 93 & $\mathrm{HCoV}$ \\
\hline 14913 & 14947 & 35 & 31 & 89 & $\mathrm{HCoV}$ \\
\hline 14933 & 15070 & 138 & 112 & 82 & $\mathrm{BCoV}$ \\
\hline 14982 & 15091 & 110 & 89 & 81 & IBV \\
\hline 14986 & 15055 & 70 & 64 & 92 & MHV \\
\hline 15062 & 15093 & 32 & 29 & 91 & $\mathrm{HCoV}$ \\
\hline 15123 & 15173 & 51 & 43 & 85 & TGEV \\
\hline 15210 & 15232 & 23 & 22 & 96 & PEDV \\
\hline 15210 & 15238 & 29 & 27 & 94 & $\mathrm{BCoV}$ \\
\hline 15210 & 15253 & 44 & 40 & 91 & IBV \\
\hline 15417 & 15482 & 66 & 57 & 87 & $\mathrm{BCoV}$ \\
\hline 15417 & 15457 & 41 & 37 & 91 & IBV \\
\hline 15420 & 15479 & 63 & 55 & 88 & MHV \\
\hline 15611 & 15682 & 72 & 64 & 89 & PEDV \\
\hline 15624 & 15670 & 47 & 42 & 90 & $\mathrm{HCoV}$ \\
\hline 15633 & 15672 & 40 & 35 & 88 & TGEV \\
\hline 15729 & 15770 & 42 & 40 & 96 & MHV \\
\hline 15765 & 15817 & 53 & 46 & 87 & $\mathrm{HCoV}$ \\
\hline 15852 & 15908 & 57 & 49 & 86 & MHV \\
\hline 17088 & 17125 & 38 & 35 & 93 & IBV \\
\hline 17688 & 17714 & 27 & 25 & 93 & TGEV \\
\hline 17757 & 17800 & 44 & 39 & 89 & PEDV \\
\hline 17783 & 17809 & 27 & 25 & 93 & $\mathrm{HCoV}$ \\
\hline 18558 & 18577 & 20 & 20 & 100 & PEDV \\
\hline 18771 & 18847 & 77 & 65 & 85 & TGEV \\
\hline 18784 & 18833 & 50 & 44 & 88 & $\mathrm{HCoV}$ \\
\hline 19102 & 19132 & 31 & 29 & 94 & IBV \\
\hline 19113 & 19132 & 20 & 20 & 100 & $\mathrm{HCoV}$ \\
\hline 19146 & 19252 & 107 & 87 & 82 & MHV \\
\hline 19201 & 19252 & 52 & 45 & 87 & IBV \\
\hline 19206 & 19253 & 48 & 44 & 92 & $\mathrm{BCoV}$ \\
\hline 19396 & 19420 & 25 & 24 & 96 & MHV \\
\hline
\end{tabular}


Table 7 (continued)

\begin{tabular}{lllccl}
\hline $\begin{array}{l}\text { Beginning in } \\
\text { SARS }\end{array}$ & $\begin{array}{l}\text { Ending in } \\
\text { SARS }\end{array}$ & Length & Identity & $\begin{array}{l}\text { Match percent } \\
(\%)\end{array}$ & Source \\
\hline 19396 & 19420 & 25 & 24 & 96 & BCoV \\
19517 & 19564 & 48 & 42 & 88 & MHV \\
19548 & 19588 & 41 & 37 & 91 & TGEV \\
20709 & 20746 & 38 & 34 & 90 & MHV \\
20712 & 20747 & 36 & 33 & 92 & IBV \\
20793 & 20839 & 47 & 41 & 88 & HCoV \\
20797 & 20827 & 31 & 28 & 91 & PEDV \\
25062 & 25084 & 23 & 22 & 96 & IBV \\
25068 & 25088 & 21 & 21 & 100 & MHV \\
25068 & 25090 & 23 & 22 & 96 & TGEV \\
25068 & 25090 & 23 & 22 & 96 & BCoV \\
29593 & 29621 & 29 & 29 & 100 & IBV \\
\hline
\end{tabular}

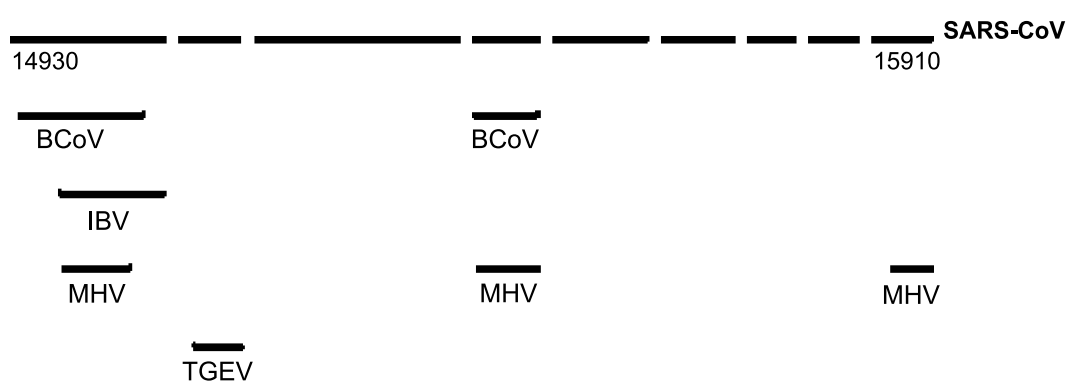

PEDV

$\overline{\mathrm{HCoV}}$

Fig. 5. Mosaic structure of the region 14930-15908 in SARS-CoV genome. Six coronaviruses (IBV, BCoV, HCoV, MHV, PEDV and TGEV) are potential parents of SARS-CoV, where SARS-CoV-severe acute respiratory syndrome-associated coronavirus, PEDVporcine epidemic diarrhea virus, TGEV-transmissible gastroenteritis virus, BCoV-bovine coronavirus, HCoV-human coronavirus, MHV-murine hepatitis virus, and IBV-avian infectious bronchitis virus

indicated that there are 38 nucleotide polymorphisms (26 of them are nonsynonymous) in the $\mathrm{S}$ genes of human SARS-CoV viruses compared to animal SARS-CoV-like viruses, although the additional 29 nucleotide sequence in the animal viruses exists in ORF10, not in the S protein. These polymorphisms could be responsible for changes in host range and tissue tropism among coronaviruses, for a single nucleotide change can dramatically alter the behaviour of the virus [35].

Based on phylogenetic techniques and BOOTSCAN recombination analysis Stavrinides and Guttman [32] indicated that the replicase of SARS-CoV was a mammalian-like origin, the $\mathrm{M}$ and $\mathrm{N}$ proteins have an avian-like origin, and the $\mathrm{S}$ protein has a mammalian-avian mosaic origin. While in the present study 
we used phylogenetic analysis and 7 recombination detection methods, including the powerful methods of MAXCHI and GENECONV among 14 methods studied (SIMPLOT (BOOTSCAN), GENECONV, HOMOPLASY TEST, PIST, MAXCHI, CHIMAERA, PHYPRO, PLATO, RDP, RECPARS, RETICULATE, RUNS TEST, SNEATH TEST, TRIPLE) [23, 24], to conduct whole genomewide recombination analysis. We identified seven putative recombination regions, which encompass, in terms of proteins involved, replicase 1A, replicase 1B and the spike glycoprotein. Stavrinides and Guttman [32] primarily inferred the occurrence of recombination qualitatively, but did not identify the precise recombination region in the protein involved (the $\mathrm{S}$ protein is an exception, they identified a recombination region in S protein, located between nucleotides 2472 and 2694 of the S protein, i.e. between nucleotides 23963 and 24185 of the SARS$\mathrm{CoV}$ genome, basically covered by the last recombination region for $\mathrm{S}$ protein (Table 6)). Most importantly, each of our recombination regions is identified by at least 3 methods, because one should not rely too much on a single method, as suggested in [23]. In general, we believe two studies lead to the overall conclusion: the evolution of SARS-CoV has involved recombination.

The recombination event in the replicase is related to the fact that the RNA polymerase of coronaviruses utilize a discontinuous transcription mechanism to synthesize mRNAs. The viral polymerase must jump between different RNA templates regularly during positive- or negative-strand RNA synthesis and depending on the rejoining sites, the resultant RNA recombination will be either homologous or nonhomologous. This is the copy-choice model of recombination in RNA viruses [13, 27, 31, 34]. The recombination event in S protein is certainly important since this allows the virus to alter surface antigenicity and escape immunesurveillance in the animals, thus adapting to a human host.

The existence of SARS-CoV-like viruses (99.8\% homology to human SARS$\mathrm{CoV}$ ) in several wild animals in a live animal market in Guangdong [7] indicated that interspecies transmission among the human and animal SARS-CoV-like viruses had occurred. The mutation analysis of sequence variations among these isolates will help identify the genetic signature of SARS virus strains when a sufficient amount of sequence data is available.

The very fact that several species of animals are affected does not allow one to trace directly the origin of the virus as endemic in one of these species, but, rather, might be indicative that animals and men might have been contaminated by a virus from a common origin, presumably located in animal food present in local markets in the Guangdong province. Investigating a wide variety of animal coronaviruses, especially in relation to rodents, birds, snakes and farm animals, would be interesting with regard to the origin of the SARS-CoV that caused disease in humans.

Finally, a challenging question arises. What is the molecular basis of recombination in SARS-CoV? Many requirements are needed for recombination to occur: (1) Two coronaviruses can infect a host simultaneously and continue to replicate without interference with each other; (2) Sufficient nucleotide identity between these genomes is essential for genome-switching to occur during RNA replication; (3) The proteins arising from recombination must be functional; (4) The recombinant virus must have some selective advantage for its survival. That 
is, the recombination that creates a successful "new" coronavirus is probably a rare event. So, we must stress that the potential recombination events in SARS-CoV, identified in the present study, are most likely "old" events, which may represent the events that occurred thousands of years ago. Although the recent findings indicated that SARS-CoV did exist in a number of wild animals [7], we have not yet determined where these SARS-CoV-like virus strains come from.

\section{Acknowledgement}

We wish to thank the Hong Kong Innovation and Technology Fund for supporting the present research.

\section{References}

1. Anand K, Ziebuhr J, Wadhwani P, Mesters JR, Hilgenfeld R (2003) Coronavirus main proteinase $\left(3 \mathrm{CL}^{\text {pro }}\right)$ structure: basis for design of anti-SARS drugs. Science 300: 1763-1767

2. Anderson JP, Rodrigo AG, Learn GH, Madan A, Delahunty C, Coon M, Girard M, Osmanov S, Hood L, Mullins JI (2000) Testing the hypothesis of a recombinant origin of human immunodeficiency virus type 1 subtype E. J Virol 74: 10752-10765

3. Carr JK, Salminen MO, Koch C, Gotte D, Artenstein AW, Hegerich PA, Louis DSt, Burke DS, McCutchan FE (1996) Full-length sequence and mosaic structure of a human immunodeficiency virus type 1 isolate from Thailand. J Virol 70: 5935-5943

4. Cavanagh D, Davis PJ (1988) Evolution of avian coronavirus IBV: sequence of the matrix glycoprotein gene and intergenic region of several serotypes. J Gen Virol 69: 621-629

5. Cavanagh D, Davis PJ, Cook JKA (1992) Infectious bronchitis virus: evidence for recombination within the Massachusetts serotype. Avian Pathol 21: 401-408

6. Gao F, Robertson DL, Morrison SG, Hui H, Craig S, Decker J, Fultz PN, Girard M, Shaw GM, Hahn BH, Sharp PM (1996) The heterosexual human immunodeficiency virus type 1 epidemic in Thailand is caused by an intersubtype (A/E) recombinant of African origin. J Virol 70: 7013-7029

7. Guan Y, Zheng BJ, He YQ, Liu XL, Zhuang ZX, Cheung CL, Luo SW, Li PH, Zhang LJ, Guan YJ, Butt KM, Wong KL, Chan KW, Lim W, Shortridge KF, Yuen KY, Peiris JSM, Poon LLM (2003) Isolation and characterization of viruses related to the SARS coronavirus from animals in southern China. Science 302(5643): 276-278

8. Husmeier D, McGuire G (2002) Detecting recombination with MCMC. Bioinformatics 18: S345-S353

9. Husmeier D, Wright F (2001) Probabilistic divergence measures for detecting interspecies recombination. Bioinformatics 17: 1-8

10. Jia W, Karaca K, Parrish CR, Naqi SA (1995) A novel variant of avian infectious bronchitis virus resulting from recombination among three different strains. Arch Virol 140(2): 259-271

11. Kottier SA, Cavanagh D, Britton P (1995) Experimental evidence of recombination in coronavirus infectious bronchitis virus. Virology 213(2): 569-580

12. Ksiazek TG, Erdman D, Goldsmith CS, Zaki SR, Peret T, Emery S, Tong S, Urbani C, Comer JA, Lim W et al. (2003) A novel coronavirus associated with severe acute respiratory syndrome. N Engl J Med 348: 1953-1966

13. Lai MMC (1992) RNA recombination in animal and plant viruses. Microbiol Rev 56: $61-79$ 
14. Lai MMC (1996) Recombination in large RNA viruses: coronaviruses. Semin Virol 7: 381-388

15. Lipsitch M, Cohen T, Cooper B, Robins JM, Ma S, James L, Gopalakrishna G, Chew SK, Tan CC, Samore MH et al. (2003) Transmission dynamics and control of severe acute respiratory syndrome. Science 300(5627): 1966-1970

16. Markino S, Keck JG, Stohlman SA, Lai MMC (1986) High-frequency RNA recombination of murine coronaviruses. J Virol 57: 729-737

17. Marra MA, Jones SJM, Astell CR, Holt RA, Brooks-Wilson A, Butterfield YSN, Khattra J, Asano JK, Barber SA, Chan SY et al. (2003) The genome sequence of the SARSassociated coronavirus. Science 300: 1399-1404

18. Martin D, Rybicki E (2000) RDP: detection of recombination amongst aligned sequences. Bioinformatics 16: 562-563

19. Maynard Smith J (1992) Analyzing the mosaic structure of genes. J Mol Evol 34: 126-129

20. McGuire G, Wright F, Prentice M (1997) A graphical method for detecting recombination in phylogenetic data sets. Mol Biol Evol 14: 1125-1131

21. Millman KL, Tavare S, Dean D (2001) Recombination in the ompA gene but not the omcB gene of Chlamydia contributes to serovar-specific differences in tissue tropism, immune surveillance, and persistence of the organism. J Bacteriol 183: 5997-6008

22. Ng TW, Turinici G, Danchin A (2003) A double epidemic model for the SARS propagation. BMC Infect Dis 3: 19

23. Posada D (2002) Evaluation of methods for detecting recombination from DNA sequences: Empirical data. Mol Biol Evol 19: 708-717

24. Posada D, Crandall KA (2001) Evaluation of methods for detecting recombination from DNA sequences: Computer simulations. Proc Natl Acad Sci USA 98: 13757-13762

25. Rota PA, Oberste MS, Monroe SS, Nix WA, Campagnoli R, Icenogle JP, Penaranda S, Bankamp B, Maher K, Chen MH et al. (2003) Characterization of a novel coronavirus associated with severe acute respiratory syndrome. Science 300: 1394-1399

26. Salminen MO, Carr JK, Burke DS, McCutchan FE (1995) Identification of breakpoints in intergenotypic recombinants of HIV type 1 by Bootscanning. AIDS Res Hum Retrovir 11: $1423-1425$

27. Sawicki SG, Sawicki DL (1998) A new model for coronavirus transcription. Adv Exp Med Biol 440: 215-219

28. Sawyer S (1989) Statistical tests for detecting gene conversion. Mol Biol Evol 6: 526-538

29. Snijder EJ, Bredenbeek PJ, Dobbe JC, Thiel V, Ziebuhr J, Poon LLM, Guan Y, Rozanov M, Spaan WM, Gorbalenya AE (2003) Unique and conserved features of genome and proteome of SARS-coronavirus, an early split-off from the coronavirus group 2 lineage. J Mol Biol 331: 991-1004

30. Snijder EJ, den Boon JA, Horzinek MC, Spaan WJ (1991) Comparison of the genome organization of toro- and coronaviruses: evidence for two nonhomologous RNA recombination events during Berne virus evolution. Virology 180(1): 448-452

31. Spaan W, Delius H, Skinner MA, Armstrong J, Rottier P, Smeekens S, Siddell SG, van der Zeijst B (1984) Transcription strategy of coronaviruses: fusion of non-contiguous sequences during mRNA synthesis. Adv Exp Med Biol 173: 173-186

32. Stavrinides J, Guttman DS (2004) Mosaic evolution of the severe acute respiratory syndrome coronavirus. J Virol 78(1): 76-82

33. Thompson JD, Higgins DG, Gibson TJ (1994) CLUSTAL W: improving the sensitivity of progressive multiple sequence alignment through sequence weighting, positions-specific gap penalties and weight matrix choice. Nucleic Acids Res 22: 4673-4680

34. van Marle G, van der Most RG, van der Straaten T, Luytjes W, Spaan WJ (1995) Regulation of transcription of coronaviruses. Adv Exp Med Biol 380: 507-510 
35. Vogel G (2003) Flood of sequence data yields clues but few answers. Science 300: $1062-1063$

36. Wang L, Junker D, Collisson EW (1993) Evidence of natural recombination within the S1 gene of infectious bronchitis virus. Virology 192(2): 710-716

37. Wang L, Junker D, Hock L, Ebiary E, Collisson EW (1994) Evolutionary implications of genetic variations in the S1 gene of infectious bronchitis virus. Virus Res 34(3): $327-338$

38. Wang L, Xu Y, Collisson EW (1997) Experimental confirmation of recombination upstream of the S1 hypervariable region of infectious bronchitis virus. Virus Res 49: $139-145$

39. Worobey M, Rambaut A, Holmes EC (1999) Widespread intra-serotype recombination in natural populations of dengue virus. Proc Natl Acad Sci USA 96: 7352-7357

Author's address: Dr. Xue Wu Zhang, HKU-Pasteur Research Centre Ltd., Dexter H.C. Man Building, 8 Sassoon Road, Pokfulam, Hong Kong, P.R. China; e-mail: xwzhang@ @kucc. hku.hk 